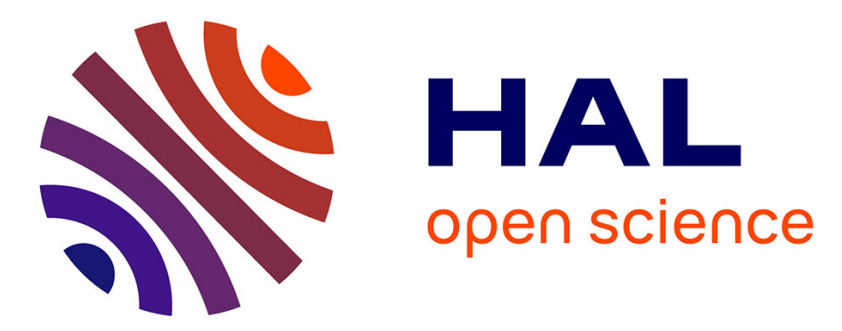

\title{
I - Ecologically responsible and efficient recycling of Pd from aqueous effluents using biosorption on biomass feedstock
}

\author{
Armelle Garcia, Pierre-Alexandre Deyris, Pauline Adler, Franck Pelissier, \\ Timothé Dumas, Yves-Marie Legrand, Claude Grison
}

\section{To cite this version:}

Armelle Garcia, Pierre-Alexandre Deyris, Pauline Adler, Franck Pelissier, Timothé Dumas, et al.. I - Ecologically responsible and efficient recycling of $\mathrm{Pd}$ from aqueous effluents using biosorption on biomass feedstock. Journal of Cleaner Production, 2021, 299, pp.126895. 10.1016/j.jclepro.2021.126895 . hal-03192680

\author{
HAL Id: hal-03192680 \\ https://hal.science/hal-03192680
}

Submitted on 11 Oct 2021

HAL is a multi-disciplinary open access archive for the deposit and dissemination of scientific research documents, whether they are published or not. The documents may come from teaching and research institutions in France or abroad, or from public or private research centers.
L'archive ouverte pluridisciplinaire HAL, est destinée au dépôt et à la diffusion de documents scientifiques de niveau recherche, publiés ou non, émanant des établissements d'enseignement et de recherche français ou étrangers, des laboratoires publics ou privés. 


\title{
I - Ecologically responsible and efficient recycling of Pd from aqueous effluents using biosorption on biomass feedstock
}

\author{
Armelle Garcia, Pierre-Alexandre Deyris, Pauline Adler, Franck Pelissier, Timothé Dumas, \\ Yves-Marie Legrand, Claude Grison*
}

Laboratory of Bio-inspired Chemistry and Ecological Innovations, UMR, CNRS-University of Montpellier, 5021, France

Keywords:

\begin{abstract}
A B S T R A C T
In the current context of the considerable interest in palladium (Pd), a new process of Pd biosorption is described with various natural materials derived from plant feedstocks. Eichhornia crassipes was chosen as a model plant for determining the thermodynamic and kinetic parameters of Pd biosorption. The optimised process was then tested on other natural materials (wheat, pine cones, coffee grounds, green tea grounds), powders derived from dead native (Mentha aquatica) and invasive aquatic plants (Pistia stratiotes, Ludwigia peploides). The competitive biosorption of other platinum group metals, i.e. $\mathrm{Pd}, \mathrm{Ru}, \mathrm{Ir}$, $\mathrm{Rh}, \mathrm{Pt}$ ) was also evaluated using E. crassipes. Moreover, selective separation of Pd, Pt, Ru and Ir was possible. Mechanistic investigations allowed us to explain the high affinity of Pd for root powder obtained from aquatic plants.
\end{abstract}

Natural feedstocks

Recovery of invasive plants

Palladium biosorption

Ecological recycling

Precious metals

\section{Introduction}

Palladium-catalysed cross-coupling methodologies to assemble $\mathrm{C}-\mathrm{C}$ and $\mathrm{C}-\mathrm{X}(\mathrm{X}=\mathrm{N}, \mathrm{O}, \mathrm{S})$ bonds between appropriately functionalized substrates have revolutionized organic chemistry, allowing transformations that were either impossible or only possible using multi-step approaches (Biffis et al., 2018). Having found widespread use in organic synthesis (2010 Nobel Prize for chemistry to R. Heck, E. Negishi and A. Suzuki) and material science, Pd-catalysed crosscoupling reactions also play an important role in the pharmaceutical, agrochemical and fine chemical industries (Torborg and Beller, 2009). However, ore deposits of Pd are rare, are mostly located in geopolitically tense areas, and are experiencing increasing demand on world markets, leading to record-high prices of Pd. Therefore, innovation in recycling this precious metal has become imperative.

The industrial recovery of palladium is mainly based on hydrometallurgical and pyrometallurgical processes with high environmental impacts (Zhang et al., 2020; Ilyas et al., 2020). In

\footnotetext{
* Corresponding author.

E-mail address: claude.grison@cnrs.fr (C. Grison).
}

hydrometallurgical processes, Pd is recovered after roasting/ burning in the presence of additives (for example, $800^{\circ} \mathrm{C} / \mathrm{NaOH}$ ) or by liquid-liquid extraction, for example with tri $n$-octylamine (a hazardous product), with hydrochloric acid coupled to strong oxidants $\left(\mathrm{HNO}_{3}, \mathrm{Cl}_{2}, \mathrm{NaOCl}\right.$, and others), and cyanide solutions, which slowly release hydrogen cyanide (a flammable and poisonous gas). Biohydrometallurgical processes such as bioleaching with cyanogenic bacteria for metal recovery have been shown to be promising for Pd. Ultrasound pretreatment preceding bioleaching by cyanogenic bacteria has been described as a promising strategy (Karim and Ting, 2020). However, the ultrasound activation did not avoid the use of nitric acid $6 \mathrm{M}$.

Pyrometallurgical processes require very high temperature $\left(2000{ }^{\circ} \mathrm{C}\right)$ or chlorination under high temperatures $\left(600-1200{ }^{\circ} \mathrm{C}\right)$ in chlorine gas (Dong et al., 2015).

The hydrometallurgical, biohydrometallurgical, pyrometallurgical processes generate solutions containing Pd ions together with numerous impurities, which must be removed. Among the widely applied techniques of separation, employing resins is the main approach.

The use of commercial resins possessing amino groups in removal of impurities requires elution with controlling $\mathrm{HCl}$ or 
various chemical reagents. Such conditions lead to issues in wastewater treatment and risks for the environment. Alternatively, synthesized chelating resins can be used, but their preparation has high environmental impacts (LeeKurniawan et al., 2020).

There exist only few recent studies on palladium recovery from wastes and minerals. The combination of Pd residue ball-milling in presence of a nano-Fe/Ca/CaO system to trap $\mathrm{Pd}$, with a froth flotation procedure, is an interesting solution. However, the flotation step requires organic solvents (Mallampati et al., 2018). According to the concept of $\mathrm{E}$ factors for reducing the environmental impact of chemical processes, the waste generated consists primarily of solvents (Sheldon, 2005). Another Pd capture process using eutectic copper was developed to recover palladium in spent catalyst material. Palladium was captured by copper in the form of a copper-palladium alloy. However, Pd recovery required heating to $1350{ }^{\circ} \mathrm{C}$ (Zhang et al., 2019).

Biosorption has emerged as an interesting option for removal or recovery of Pd from wastewaters. Common biosorbents for precious metal ions include various derivatives of chitosan (Mack et al., 2007; Chassary et al., 2005). However, the preparation of chitosan (chitin extraction, deproteination, chitin deacetylation) has a high environmental impact (Younes and Rinaudo, 2015).

These processes are unsuitable from the ecological point of view. The development of eco-friendly, cleaner, bio-based and costeffective recovery of $\mathrm{Pd}$ is imperative.

Unlike other transition metals ( $\mathrm{Zn}, \mathrm{Ni}, \mathrm{Mn}, \mathrm{Cu}, \mathrm{Co})$, no Pdhyperaccumulating plants have been reported so far, limiting the potential for recycling Pd using phytoextraction technology for industrial chemistry. However, rhizofiltration represents an alternative and ecologically viable solution for Pd recycling. Using specific aquatic plants capable of bioconcentrating Pd in roots, our group addressed the transformation of plant-derived Pd metal into green catalysts, called Eco-Pd. This work has established the dual concept of rhizofiltration/ecocatalysis as a powerful strategy for the development of efficient Pd-catalysts that can be easily recycled and reused (Clavé et al., 2017; Garel et al., 2015).

However, scaling-up of the rhizofiltration process is not easy, because it requires numerous unit operations: germination, growth, and harvesting of plants on a scale necessary to allow, phytoaccumulation of Pd in large basins. Moreover, controlling the reproducibility of rhizofiltration parameters with living plants is challenging and seems incompatible with feasibility for industrial applications. Recently, we established that $\mathrm{Zn}$ phytoaccumulation by rhizofiltration is a passive non metabolically-mediated process (Stanovych et al., 2019; Grison et al., 2018). This result suggests an opportunity to develop a more practical approach based on the direct use of dead aquatic plants through biosorption technology. This process, which significantly reduces the number of steps and uncertainties in results of the small-scale experiments conducted to data, may be better suited for large-scale industrial application. Additionally, this led us to ask whether the promising results obtained for zinc phytoaccumulation might be extended to other critical/rare metals such as Pd, Ru and Pt. It should be noted that mild experimental conditions are used to prepare the biomaterials and ecocatalysts, which is a crucial criterion for an ecologically appropriate process. In contrast to biosorption of toxic metals $(\mathrm{Cr}$, $\mathrm{Cd}, \mathrm{Cu}, \mathrm{Pb}, \mathrm{Ni}$ ), that of $\mathrm{Pd}$ has been poorly described. A few studies have examined the use of microbial biomass (bacteria, microfungi, fungi, yeasts) in a two-step process whose biosorption was followed by bioreduction of $\mathrm{Pd}^{\mathrm{II}}$ into $\mathrm{Pd}^{0}$ (Chen et al., 2018; Cui et al., 2017). Recent examples described the biosorption potential of two plants, an aquatic moss, Racomitrium lanuginosum ((Sari et al., 2009) and leaf biomass of the Indian almond tree, Terminalia catappa (Ramakul et al., 2012).

In the current context of considerable interest in recovery of $\mathrm{Pd}$, we describe here a new process of Pd biosorption using various natural materials derived from plant feedstocks. Eichhornia crassipes was first chosen as a model plant for determining the physicochemical parameters of Pd biosorption. We began to examine the biosorption potential of this ecomaterial by isotherm and kinetic studies. We then investigated effects of the amount of biosorbent and of different components of the root system and its components on Pd biosorption.

Using the most favorable conditions observed in our model system, we then envisioned conducting Pd biosorption with other natural materials, in particular biomass of dead aquatic plants, both native and invasive species. Performances of this material were compared under different conditions of initial $\mathrm{pH}$ and different biosorption procedures, batch mode and fixed-bed column. The optimal conditions of Pd biosorption were then extended to the competitive biosorption of other platinum group metals (PGM, i.e. $\mathrm{Pd}, \mathrm{Ru}, \mathrm{Ir}, \mathrm{Rh}, \mathrm{Pt}$ ). Finally, theoretical and mechanistic investigations were carried out to explain the high affinity of Pd for root powder obtained from aquatic plants.

\section{Materials and methods}

Detailed descriptions of the origin of the plants used, their transformation to obtain biomaterial, the biosorption steps and the preparation of the ecocatalysts are also described in the first section of the SI. In the first section of this document, reagents and analytical techniques are also described. Plants were either obtained from a specialized grower (Nymphaea Distribution, Le Cailar, France) or collected from various sites in the Occitanie region of France.

\subsection{Preparation of biomaterials}

Eichhornia crassipes Mart. (water hyacinth, Pontederiaceae), Mentha aquatica L. (water mint, Lamiaceae), Pistia stratiotes L. (water lettuce, Araceae), Ludwigia peploides (Kunth) P.H.Raven (creeping water-primrose, Onagraceae), pine bark and pine cones were oven-dried at $80^{\circ} \mathrm{C}$ until reaching constant weight. They were then were ground, sifted through a 1.25 mesh sieve, and washed with water $\left(3 \times 100 \mathrm{~mL} \mathrm{~g}^{-1}\right)$. They were then oven-dried $18 \mathrm{~h}$ at $80{ }^{\circ} \mathrm{C}$ before biosorption. Coffee grounds were washed several times with hot water until the filtrate became colorless and then were oven-dried $18 \mathrm{~h}$ at $80^{\circ} \mathrm{C}$ before biosorption.

\subsection{Preparation of Eco-Pd}

The dried palladium-loaded biomaterials were thermally treated at $550{ }^{\circ} \mathrm{C}$ under air for $4 \mathrm{~h}$. The resulting ecocatalysts were characterized by MP-AES analyses. The experiments were performed three times and in each of the three experiments, three samples were analysed.

\subsection{Biosorption isotherm studies}

Eichhornia crassipes was chosen as a model adsorbent for optimising the biosorption process. Solutions with different initial Pd concentrations (from 10 to $100 \mathrm{mg} . \mathrm{L}^{-1}$ ) were used in $250 \mathrm{~mL}$ batches with $250 \mathrm{mg}$ adsorbent at pH 3.0 at $293 \mathrm{~K}$. Mixtures were stirred vigorously for $2 \mathrm{~h}$. The effect of Pd concentration on the biosorbent was analysed in terms of Langmuir model and Freundlich model as described in SI.

\subsection{Biosorption kinetics}

Kinetic studies were carried out using powdered dried roots. 
Roots of $E$. crassipes were exposed to concentrations $\mathrm{C}_{0}$ of $14 \mathrm{mg} . \mathrm{L}^{-1}$ of $\mathrm{Pd}\left(0.132 \mathrm{mmol} . \mathrm{L}^{-1}\right.$ of $\left.\mathrm{Pd}\left(\mathrm{NH}_{3}\right)_{4}\left(\mathrm{NO}_{3}\right)_{2}\right)$ using different initial adsorbent loading ( 1 g.L ${ }^{-1}, 1.5$ g.L $\mathrm{L}^{-1}, 2$ g.L $\left.\mathrm{L}^{-1}\right)$. After 2 h' stirring, the powder was separated by filtration, mineralised, and analysed by MP-AES to quantify the amount of sorbed Pd $\left(\mathrm{q}_{\mathrm{mg} / \mathrm{g}}\right)$. Three replicate experiments were conducted for each set of conditions (See Table 1 in SI for details).

\section{Results and discussion}

\subsection{Biosorption isotherm studies}

As mentioned previously, E. crassipes was chosen as a model adsorbent and a comparative study was conducted with the rhizofiltration system, i.e. using $1.5 \mathrm{~g}$ of roots of a living plant. In order to understand the biosorption behaviour, we compared the amounts of biosorbed Pd on the model biomass E. crassipes, depending on the initial Pd concentration, under the previously described experimental conditions. Results are shown in Table 1 of the SI. The amount of Pd adsorbed increased with increasing concentration of Pd to reach an optimum value. Regression using the Freundlich models was rather poor while the Langmuir model gave a reasonable $R^{2}$ coefficient (SI: Table 2). Plotting the amount of biosorbed Pd at equilibrium versus the equilibrium Pd concentration in solution, as shown in Fig. 1, supports a few conclusions. First, the steep slope of the curve at low solution $C_{e}$ concentrations indicates that the number of easily accessible sites by the Pd is rather high.

A plateau in the amount of biosorbed Pd was observed when the equilibrium concentration $C_{e}$ reached $13.5 \mathrm{mg} . \mathrm{L}^{-1}$, indicating that the biosorbent was saturated and that the maximum capacity of biosorption $\mathrm{Q}_{\max }$ was reached at around $29.9 \mathrm{mg} \mathrm{g}^{-1}$. This figure is close to the maximum biosorption capacity of $R$. lanuginosum biomass $\left(37.2 \mathrm{mg} \mathrm{g}^{-1}\right.$ ) (Sheldon, 2005). It is lower than that reported for Terminalia catappa (41.86 $\mathrm{mg} \mathrm{g}^{-1}$ ) (Ramakul et al., 2012), but in that case, a hazardous treatment of biomass (concentrated sulfuric acid and neutralization) was required to reach this performance (Ramakul et al., 2012).

\subsection{Biosorption kinetics}

Because $\mathrm{Pd}(\mathrm{OH})_{2}$ precipitates, with time, at $\mathrm{pH}>3.3$ (Clavé et al., 2017), we initially studied biosorption in acidic media $\left(\mathrm{HNO}_{3}\right.$,

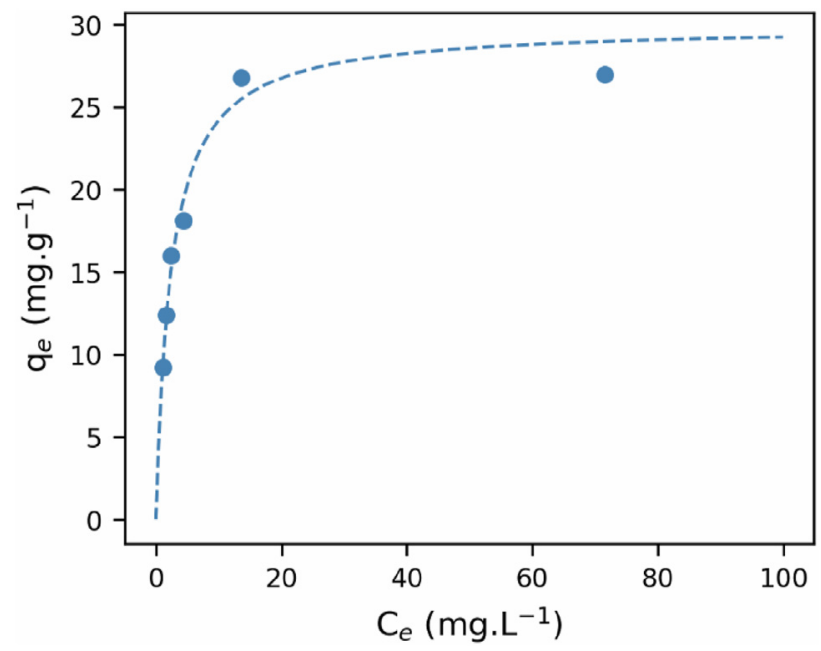

Fig. 1. Amount of biosorbed Pd at equilibrium $\left(\mathrm{q}_{\mathrm{e}}\right)$ as a function of Pd concentration in solution at equilibrium $\left(C_{e}\right)$.
$10^{-3} \mathrm{M}$ ) in batch mode under vigorous stirring. Fig. 2 illustrates the kinetics of Pd biosorption by dried roots of E. crassipes in powder form ( $\left.\mathrm{q} / \mathrm{mg} \mathrm{g}^{-1}\right)$ compared to that by rhizofiltration from the plant's living roots. These results highlight the better performance of the dried roots. It was possible to extract $12.5 \mathrm{mg}$ of Pd with $1 \mathrm{~g}$ of root powder by biosorption, while $1.5 \mathrm{~g}$ of living biomass can phytoaccumulate a maximum of $9.5 \mathrm{mg}$ of Pd by rhizofiltration (Clavé et al., 2017; Garel et al., 2015). Moreover, biosorption was faster than rhizofiltration. Using biosorption, the whole amount of Pd was bioconcentrated within $30 \mathrm{~min}$ with $2 \mathrm{~g}$ of biosorbent, whereas rhizofiltration was not total after 120 min (Fig. 1). Finally, it is important to point out that no desorption was observed in either case.

Encouraged by these results, we studied biosorption kinetics as a function of the amounts of powdered dried roots in order to determine the best conditions for full-scale batch processes of Pd removal. Three theoretical models (pseudo-first-order, pseudosecond-order and intra-particle diffusion models) were examined in order to define the parameters of the biosorption kinetics.

The capacity of biosorption at equilibrium $\left(\mathrm{q}_{\mathrm{e}}\right)$, the capacity of biosorption at time $\mathrm{t}\left(\mathrm{q}_{\mathrm{t}}\right)$, rate constants $\left(\mathrm{k}_{1}, \mathrm{k}_{2}\right.$ and $\left.\mathrm{k}_{\mathrm{id}}\right)$ and $\mathrm{R}^{2}$ were established by the linear least-squares method. Table 1 illustrates the results obtained.

The pseudo-second-order kinetic model led to the best coefficient of determination $\mathrm{R}^{2}\left(0.998<\mathrm{R}^{2}<1.000\right)$. Given this remarkably high value, we assumed that biosorption fitted best the pseudo-second order rate model:

$\frac{d q_{t}}{d t}=k_{2}\left(q_{e}-q_{t}\right)^{2}$

where $\mathrm{k}_{2}$ is the rate constant of biosorption and $\mathrm{q}_{\mathrm{e}}\left(\mathrm{mg}^{\mathrm{g}} \mathrm{g}^{-1}\right)$ is the amount of Pd biosorbed at equilibrium. Our assumption that this is the best-fitting model is consistent with experimental studies and mathematical modelling of biosorption from other natural feedstocks such as modified spent coffee grains (Cerino-Córdova et al., 2013), E. crassipes root biomass derived from activated carbon (Giri et al., 2012), tree fern (Negm et al., 2017), sugar beet pulp (Altundogan et al., 2007), and modified soybean straw (Zhu et al.,

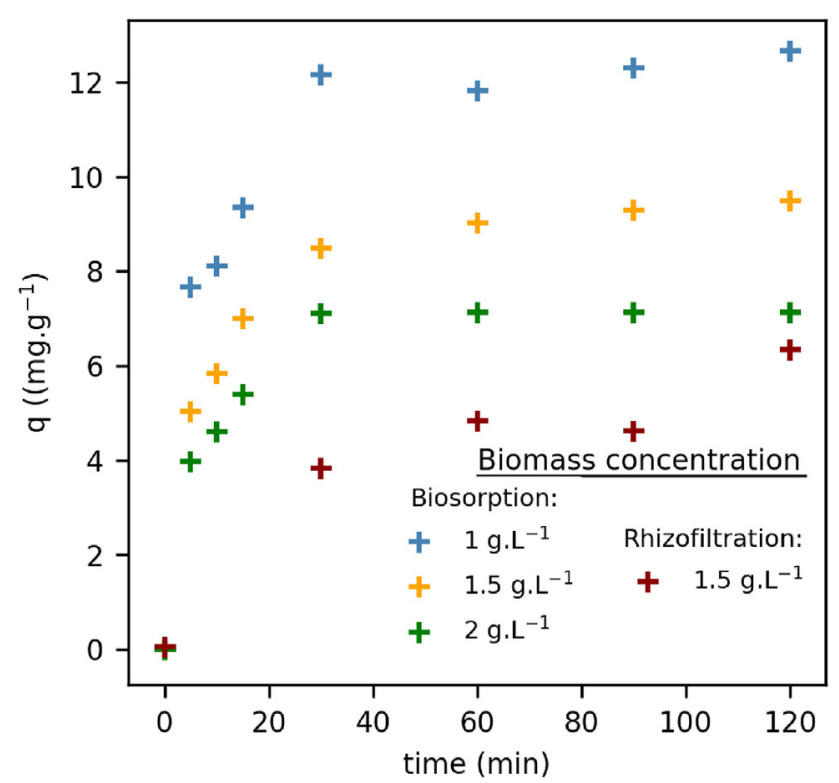

Fig. 2. Kinetics of Pd biosorption by powdered dried roots of Eichhornia crassipes and rhizofiltration from the plant's living roots. 
Table 1

Kinetic parameters obtained from different concentrations of powdered dried roots of Eichhornia crassipes and rhizofiltration by the plant's living roots.

\begin{tabular}{|c|c|c|c|c|c|c|c|c|c|}
\hline \multirow[t]{3}{*}{ Biosorbent concentration (g.L-1) } & \multicolumn{9}{|c|}{ Kinetic models } \\
\hline & \multicolumn{3}{|c|}{ Pseudo-first-order } & \multicolumn{3}{|c|}{ Pseudo-second-order } & \multicolumn{3}{|c|}{ Intra-particle diffusion model } \\
\hline & $\mathrm{k}_{1}\left(\min ^{-1}\right)$ & $\mathrm{q}_{\mathrm{e}}\left(\mathrm{mg} \cdot \mathrm{g}^{-1}\right)$ & $\mathrm{R}^{2}$ & $\mathrm{k}_{2}\left(\mathrm{~g} \cdot \mathrm{mg}^{-1} \cdot \mathrm{min}^{-1}\right)$ & $\mathrm{q}_{\mathrm{e}}\left(\mathrm{mg}_{\mathrm{g}} \mathrm{g}^{-1}\right)$ & $\mathrm{R}^{2}$ & $\mathrm{k}_{\mathrm{id}}\left(\mathrm{mg} \cdot \mathrm{g} \cdot \mathrm{min}^{-0,5}\right.$ ) & $\mathrm{q}_{\mathrm{t}}$ & $\mathrm{R}^{2}$ \\
\hline 1 & 0.0348 & 5.77 & 0.745 & 0.02173 & 12.89 & 0.9977 & 0.9544 & 4.1353 & 0.7234 \\
\hline 1.5 & 0.0398 & 5.49 & 0.9395 & 0.02351 & 9.77 & 0.9979 & 0.7497 & 2.7508 & 0.7814 \\
\hline 2 & 0.1929 & 11.58 & 0.9152 & 0.04210 & 7.36 & 0.9978 & 0.565 & 2.2738 & 0.729 \\
\hline
\end{tabular}

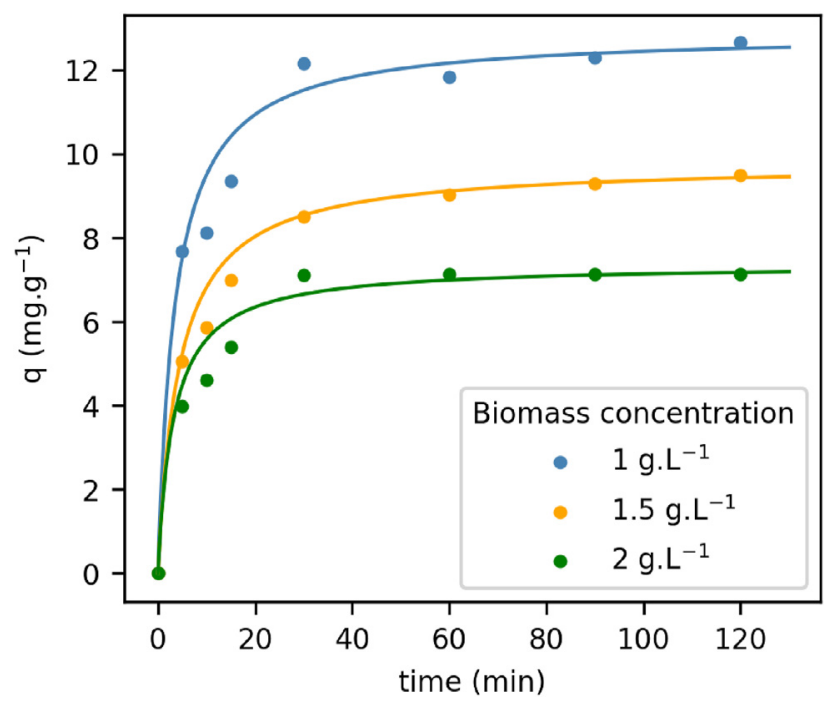

Fig. 3. Effect of contact time between Pd and biosorbent (powdered dried roots of Eichhornia crassipes) with different concentrations of biosorbents (1 g.L ${ }^{-1}, 1.5$ g.L ${ }^{-1}$ and 2 g.L $\left.{ }^{-1}\right)$.

2008).

According to the pseudo-second order model, biosorption rate is controlled by the adsorption on the internal surfaces of the pores of the plant powder. As shown in Fig. 3 and by the $k_{2}$ values (Table 1 ), biosorption was very rapid and reached equilibrium in about $30 \mathrm{~min}$.

\subsection{Effect of biosorbent amount on Eco-Pd composition}

This study had a dual objective: i) developing an efficient ecotechnology to recycle Pd and ii) transforming the Pd-enriched biosorbent into ecocatalysts, called Eco-Pd, for modern chemistry. Therefore, it was interesting to compare the performance of Pd biosorption with the \%Pd after transformation of the biosorbent ( $E$. crassipes) into Eco-Pd. The Eco-Pd was derived from a thermal treatment of powder under air flow. Thus, the composition of the residue after thermal treatment was determined (see Table S6), for details, replications and RSD). In addition to Pd, the major physiological cations ( $\mathrm{Mg}, \mathrm{Fe}, \mathrm{Al}, \mathrm{Ca}$, $\mathrm{Na}$ and $\mathrm{K}$ ) were present because of the bio-sourced origin of the catalyst. As shown in Fig. 4, the use of a high amount of biosorbent resulted in the dilution of Pd by physiological mineral elements ( $\mathrm{Na}, \mathrm{K}, \mathrm{Mg}, \mathrm{Ca}$ ). When 1 g. $\mathrm{L}^{-1}$ of biosorbent was used, an interesting compromise could be obtained between efficient biosorption of a $14 \mathrm{mg} . \mathrm{L}^{-1} \mathrm{Pd}$ solution and high Pd loading (27.76\%) in thermal residues. This concentration was greater than that of Eco-Pd derived from rhizofiltration (25.29\%).

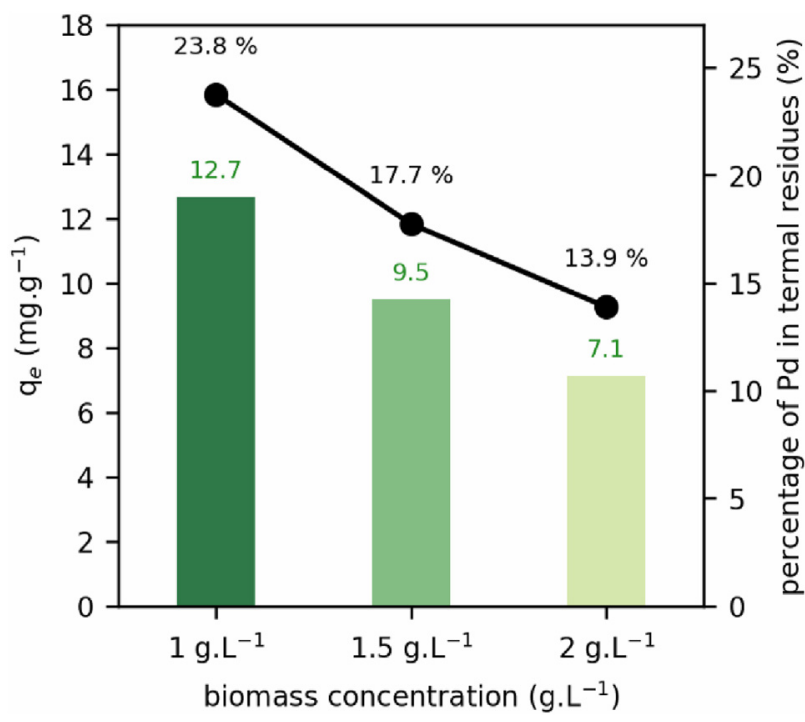

Fig. 4. Performance of Pd biosorption with different amounts of biosorbent (powdered dried roots of $E$. crassipes).

\subsection{Effect of the different parts of E. crassipes root system and its} components

The performances of different parts of the E. crassipes root system prepared in different ways (stems, dried roots in native form, dried whole root, powdered dried roots and powdered dried rootlets) were established. Fig. 5 summarizes the main results with 1 g.L $\mathrm{L}^{-1}$ of biomass and $14 \mathrm{mg} . \mathrm{L}^{-1}$ of Pd.

Performance differed markedly for different parts of the root system. Rootlets were more efficient than roots, the latter being more efficient than stems. Grinding the roots boosted biosorption by facilitating the internal distribution of Pd.

\subsection{Extension of biosorption to other ecomaterials ( 1 g.L $\left.L^{-1}\right)$}

Previously, we demonstrated that E. crassipes roots are rich in carboxylate functions. It seemed interesting to test for correlations between biosorption performances and the abundance of carboxylate functions (Stanovych et al., 2019; De Laet et al., 2019). Consequently, we investigated different materials derived from plant feedstocks. They may be divided into four groups:

- plants rich in cellulose: crude cellulose (group 1);

- plants rich in lignin: lignin extracted from wheat straw (see SI for more details), pine cones (group 2);

- wastes rich in tannins: coffee grounds, green tea grounds (group 3);

- green algae, powdered dead roots of M. aquatica, E. crassipes, P. stratiotes, L. peploides, and Nymphaea alba L. (white water lily, Nymphaeaceae), rich in carboxylate functions (group 4). 


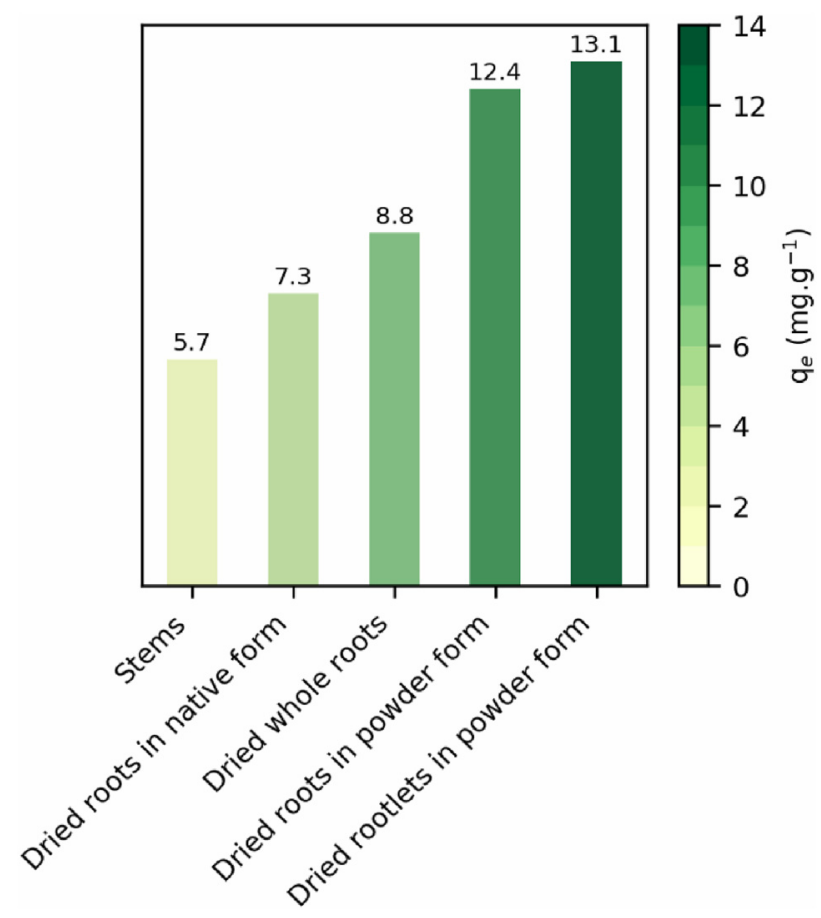

Fig. 5. Performances of Pd biosorption with different parts of the Eichhornia crassipes root system, prepared in different ways.

Results of biosorption with these other ecomaterials are summarized in Fig. 6.

Cellulose and ecomaterials rich in tannins (coffee grounds and green tea grounds) adsorbed small amounts of Pd $\left(2.7-7.0 \mathrm{mg} \mathrm{g}^{-1}\right)$. However, Pd biosorption was higher using ecomaterials rich in lignin (group 2) and aquatic plants (group 4) and to a lesser extent with green algae. Powdered roots of N. alba, E. crassipes, P. stratiotes, L. peploides and M. aquatica can remove from $91 \%$ to $97 \%$ Pd from aqueous solution within $2 \mathrm{~h}$ and using 1 g.L. $\mathrm{L}^{-1}$ of biosorbent. Green algae did not allow the same performance, because Pd was brought in solution by soluble fragments of algae. The high Pd sorption by pine cones $(96 \%)$ is notable. A preliminary conclusion from this work is that biosorbents rich in carboxylic functions perform best.

\subsection{Effect of $\mathrm{pH}$}

The $\mathrm{pH}$ of the aqueous solution might be an important parameter modulating the biosorption capacity of a natural sorbent.

The best operational conditions were determined based on two parameters that seem to vary in opposite ways:

i) As mentioned previously, at $\mathrm{pH}>3.3$, the precipitation of $\mathrm{Pd}$ salts was previously reported (Clavé et al., 2017). So it was fair to assume that precipitation of the metallic species would prevent efficient adsorption on the biomaterials.

ii) Nonetheless, we have recently shown that materials based on roots of aquatic plants are rich in carboxylate functions (Stanovych et al., 2019; De Laet et al., 2019). This fact could make roots of our group 4 plants more suitable than the biosorbents of other groups for the biosorption of Pd, owing to their stronger affinity for transition metals based on the formation of metal carboxylate salts. At $\mathrm{pH}<3$, the carboxyl group becomes $\mathrm{COOH}$, potentially reducing biosorption efficiency. For this reason, operating the biosorption in an acidic aqueous solution could hinder adsorption of Pd.
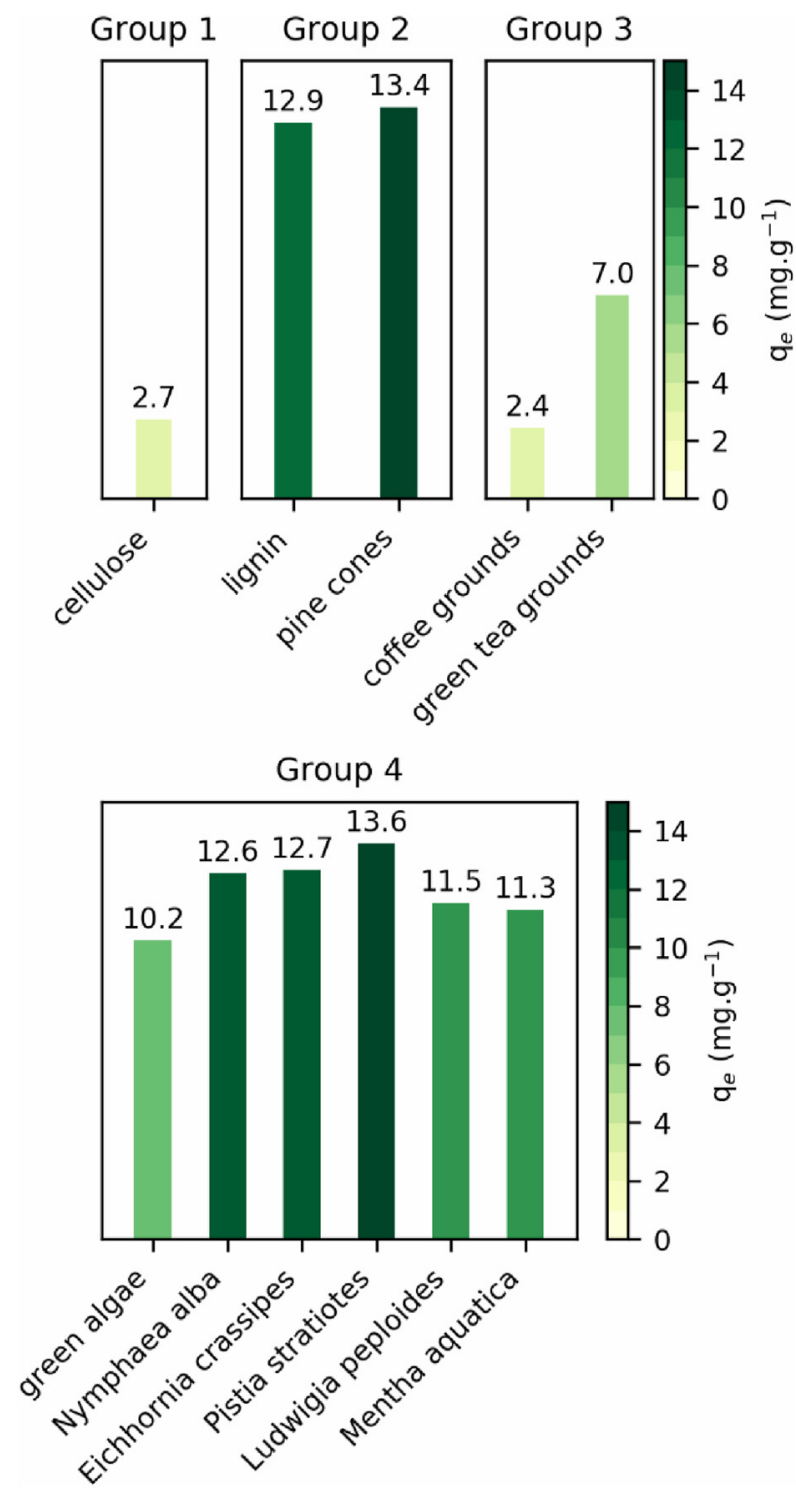

Fig. 6. Biosorption of $\mathrm{Pd}$ with different ecomaterials at $\mathrm{pH}=3$.

In this study, kinetic studies showed that Pd biosorption with powdered dried roots was very rapid, and might be completed before significant precipitation occurs. A material balance between the amount of Pd biosorbed in plant powder and the amount of Pd removed from solution was performed in order to verify if there was precipitation of $\mathrm{Pd}(\mathrm{OH})_{2}$. The data suggested that in these conditions, biosorption was faster than precipitation. This observation is rather unusual and interesting, as many assessments of biosorbents in the literature have shown that adjustment to $\mathrm{pH}<6$ was required (Giri et al., 2012; Altundogan et al., 2007; Zhu et al., 2008). Our results show that it is not necessary to work under acidic conditions.

Requirement for an acidic $\mathrm{pH}$ is undesirable in green chemistry. Ir therefore seemed interesting to determine the effect of $\mathrm{pH}$ on biosorption and to check whether it is necessary to work under acidic conditions. Thus, comparative experiments were undertaken at $\mathrm{pH}=3$ and $\mathrm{pH}=7$ with biosorbents that performed best under standard conditions $\left(\mathrm{Pd}\left(\mathrm{NO}_{3}\right)_{2} \cdot 4 \mathrm{NH}_{3}\right.$ at $0.132 \mathrm{mmol} . \mathrm{L}^{-1}$ : $[\mathrm{Pd}]=14 \mathrm{mg} . \mathrm{L}^{-1}$, E. crassipes powdered dried roots: $\left.1 \mathrm{~g} . \mathrm{L}^{-1}\right)$.

The results are shown in Fig. 7 (See SI Table 9 for MP-AES 


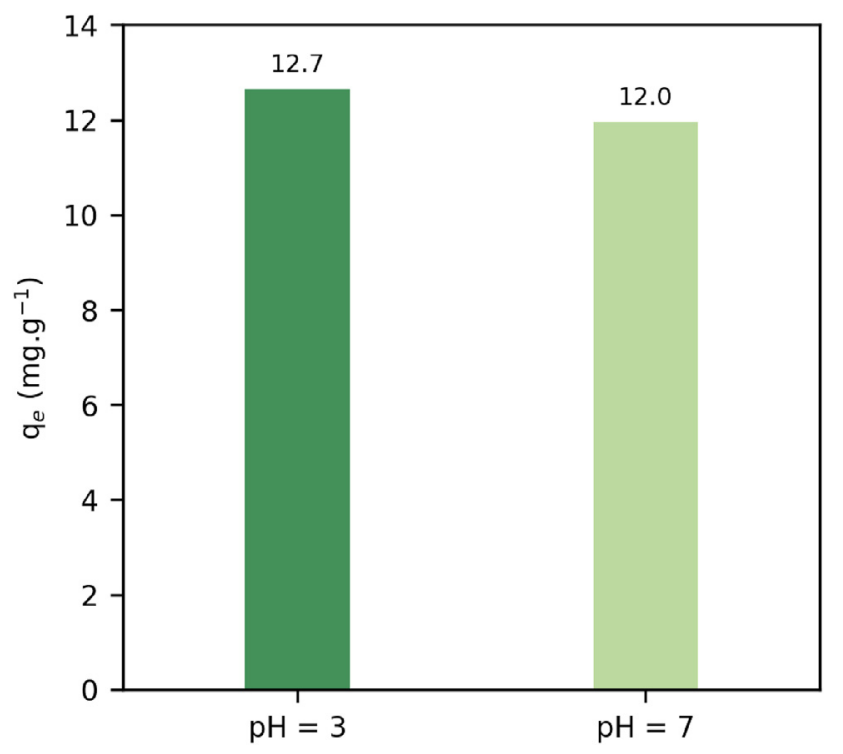

Fig. 7. Performance of Pd biosorption of E. crassipes powdered dried roots at $\mathrm{pH} 3$ and $\mathrm{pH} 7$ (100\% Pd biosorption obtained when $\left.\mathrm{q}_{\mathrm{e}}=14 \mathrm{mg} \mathrm{g}^{-1}\right)$.

assessments with replications and RSD).

No significant difference in Pd biosorption could be measured between $\mathrm{pH}=3$ and $\mathrm{pH}=7$ (12.7 and $12.0 \mathrm{mg} \mathrm{g}^{-1}$ respectively). In both cases, biosorption was high (around 90\%). This allows us to conclude that, in our experimental conditions, it is not critical to operate the biosorption at $\mathrm{pH}<3$, even when utilising carboxylaterich biomass.

\subsection{Comparative study of batch mode and fixed-bed column}

Based on the results presented above, a study comparing batch mode and fixed-bed column was performed at $\mathrm{pH}=7$ with the best-performing biosorbents $\left(1 \mathrm{~g} . \mathrm{L}^{-1}\right)$. The results are presented in Fig. 8 (See SI Table 11 for details).

In most cases, the results showed that the column mode led to a slight increase in sorption performance. A factor that may contribute to this effect is the solution's concentration, which continuously decreases in the batch mode, unlike in the column system. As seen in the kinetic studies, biosorption was rapid and a short time of residence (non-limiting step) was sufficient to reach equilibrium in column mode.

\subsection{Environmental performance of the methodology}

We evaluated the environmental performance of our methodology. For this, we compared our approach with seven methodologies (some classical and some more innovative) in terms of criteria that are most commonly considered as limitations to the environmental sustainability of chemical procedures, such as their dependence on the use of high temperatures, or of toxic solvents or reagents. For example, both high temperatures and oxidants are used for Pd recovery in pyrometallurgy, which thus cannot be considered as entirely ecologically appropriate. Conversely, this work presents a method where none of these environmentally "unfriendly" parameters are needed and which can therefore be considered as "green" and cleaner that other reported processes (Table 2).

The sorbents used in this study were renewable resources that can be obtained at no cost and are abundant in nature. Their preparation did not require any chemical or enzymatic treatment.
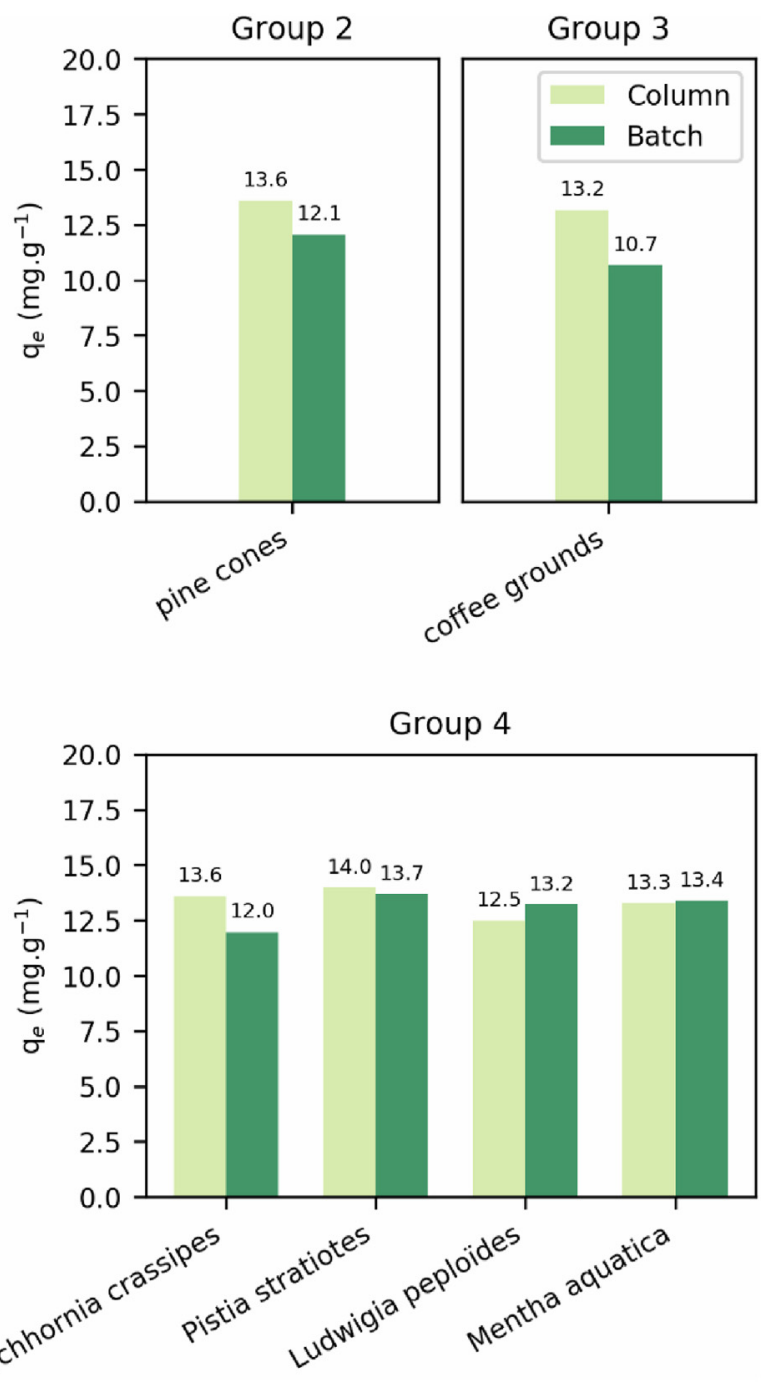

Fig. 8. Comparative study of Pd biosorption performance with batch mode and fixedbed column.

After drying in the sun, a simple grinding allowed obtaining vegetal filters. The process was direct, very easy to implement and efficient, even at neutral $\mathrm{pH}$. Consequently, no acid or basic treatment was required, which avoided the formation of wastewaters and inorganic wastes. No heating, hazardous additives, oxidants, solvent or other reagents were required. The process is completely natural. Additionally, the use of E. crassipes, $P$. stratiotes, and $L$. peploides as plant filters constitutes an opportunity for recovering Pd using invasive plants and provides strong motivation for their harvest and thereby the control of their proliferation. It is therefore, in every respect, an ecological and environmentally friendly methodology.

\subsection{Recovery of platinum group metals by selective biosorption}

Precious metals such as $\mathrm{Pd}, \mathrm{Rh}, \mathrm{Pt}, \mathrm{Ru}$, and $\mathrm{Ir}$ are essential for many chemical processes and create high added value for the chemical industry (Hunt et al., 2015). These metals are commonly found in the same ores (i.e. stibiopalladinite, cooperite, braggite) (Verryn and Merkle, 1994). Therefore, we first tested the recovery of each of these metals individually with the model biosorbent, powder derived from $E$. crassipes. In a second step, the selective 
Table 2

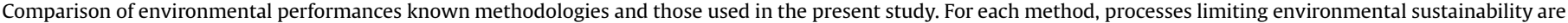
marked in red if they are required for the technique and in green if they are not.

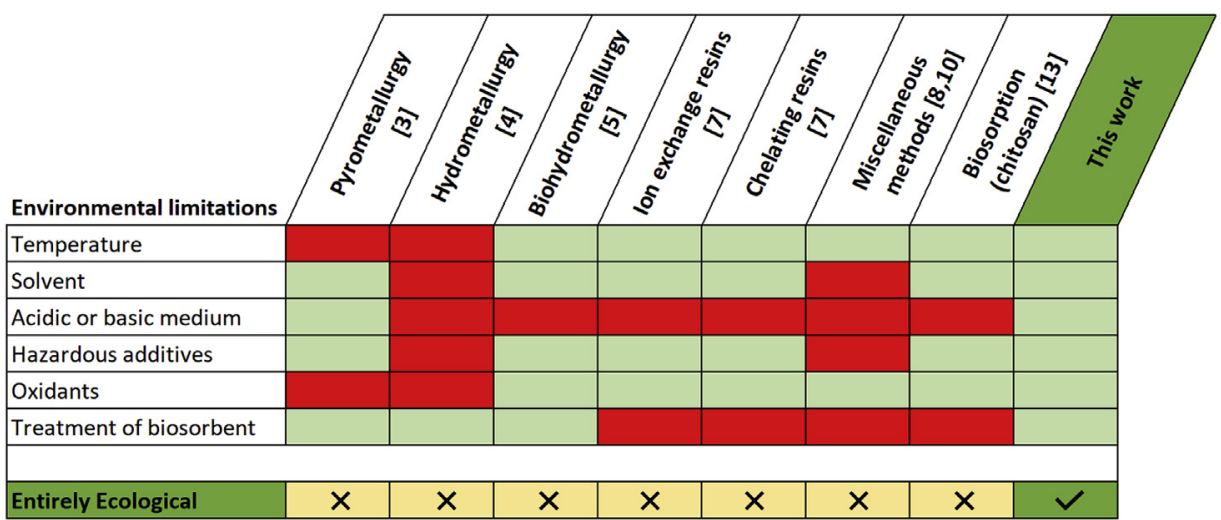

adsorption of platinoids was studied using a ternary solution containing $\mathrm{Pd}, \mathrm{Rh}$ and $\mathrm{Pt}$, in a 1:1:1 $\mathrm{M}$ ratio.

The initial palladium concentration was fixed to $14 \mathrm{mg} . \mathrm{L}^{-1} \mathrm{Pd}$, and concentrations of the other platinoids were varied to get similar molar ratios. Experiments were performed with the objective of determining the biosorption capacity of each PGM, while in competition. The percent biosorption of PGMs (Bios $\mathrm{s}_{\mathrm{i}}$, Eq. (2)), was determined by MP-AES assessments, according to equation (2) established by Chen et al. (2011) (see SI Table 12, MP-AES assessments with replications and RSD).

$\operatorname{Bios}_{\mathrm{i}}=\frac{\left(\mathrm{C}_{0}-\mathrm{C}_{\mathrm{e}}\right)_{\mathrm{i}}}{\mathrm{C}_{0, \mathrm{i}}} \times 100$

where $\mathrm{C}_{0}(0.14 \mathrm{mM})$ and $\mathrm{C}_{\mathrm{e}}(\mathrm{x} \mathrm{mM})$ are the initial and final metal concentrations in $1 \mathrm{~L}$ of solution and $1 \mathrm{~g}$ of dried root of $E$. crassipes.

The results are presented in Fig. 9.

While Ru and Ir were not biosorbed in only negligible quantities, $\mathrm{Pd}, \mathrm{Rh}$ and Pt each had an interesting and different affinity for the plant powder. Taken individually, biosorption capacity for Pd (88.8\%) was greater than that for Rh (67.6\%), and Pt (64.3\%). The greater affinity of Pd over Rh and Pt for E. crassipes powdered roots

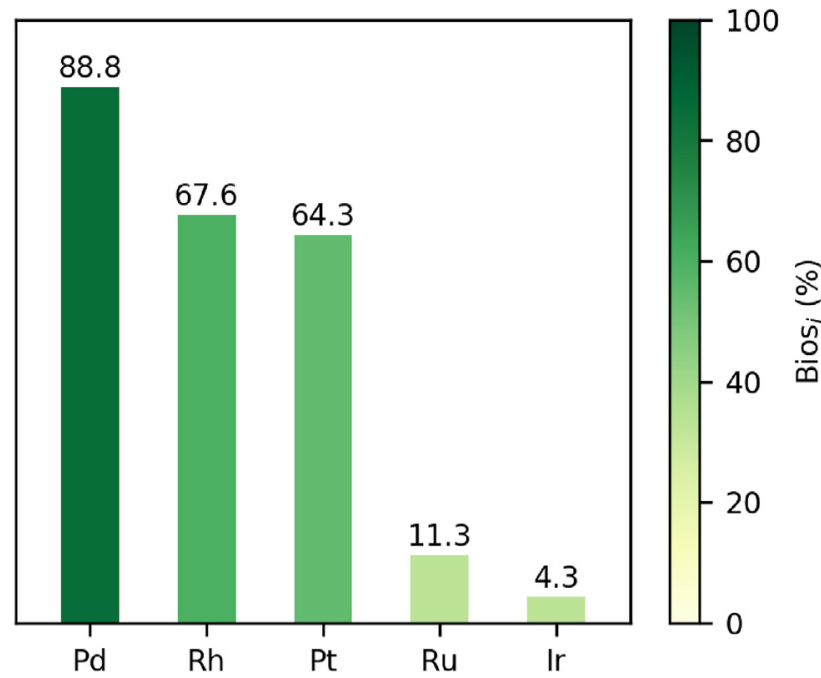

Fig. 9. Percent biosorption of Pd, Rh and Pt by powdered dried root of E. crassipes, in competitive conditions. was interesting in terms of biosorption selectivity. Therefore, we carried out the competitive biosorption of these three PGMs with an equimolar ratio $(0.132 \mathrm{mmol})$ in 1 g. $\mathrm{L}^{-1}$ suspension of biosorbent (Fig. 10).

The results shown in Fig. 10 (see SI Table 13 for detailed data) confirm that the biosorption of Pd was highly efficient. In the competitive experiment, with 1 g.L $\mathrm{L}^{-1}$ of biosorbent, $57.5 \%$ of Pd was successfully removed. This was substantially lower than the level reached with a single-component solution, probably due to the presence of the two other PGMs (Pd: $0.132 \mathrm{mmol}^{-1}$, Rh: $0.132 \mathrm{mmol} . \mathrm{L}^{-1}$, Pt: $0.132 \mathrm{mmol} . \mathrm{L}^{-1}$ ) that were introduced using the same amount of biosorbent ( 1 g. $\left.\mathrm{L}^{-1}\right)$. In competitive conditions, biosorption capacity of PGMs to this biosorbent can be ranked as follows: Pd $>$ Rh $>$ Pt. Under selected experimental conditions, a separation selectivity was calculated for Pd in comparison with Rh and Pt. This selectivity factor $\left(\mathrm{Sel}_{\mathrm{i} / \mathrm{j}}\right)$ was evaluated according to equation (3) and is depicted in Fig. 11 (Kyzas et al., 2014).

$\operatorname{Sel}_{\mathrm{i} / \mathrm{j}}=\frac{\left(\mathrm{q}_{\mathrm{e}} / \mathrm{C}_{\mathrm{e}}\right)_{\mathrm{i}}}{\left(\mathrm{q}_{\mathrm{e}} / \mathrm{C}_{\mathrm{e}}\right)_{\mathrm{j}}}$

The index i corresponds to Pd and index $\mathrm{j}$ refers to the remaining

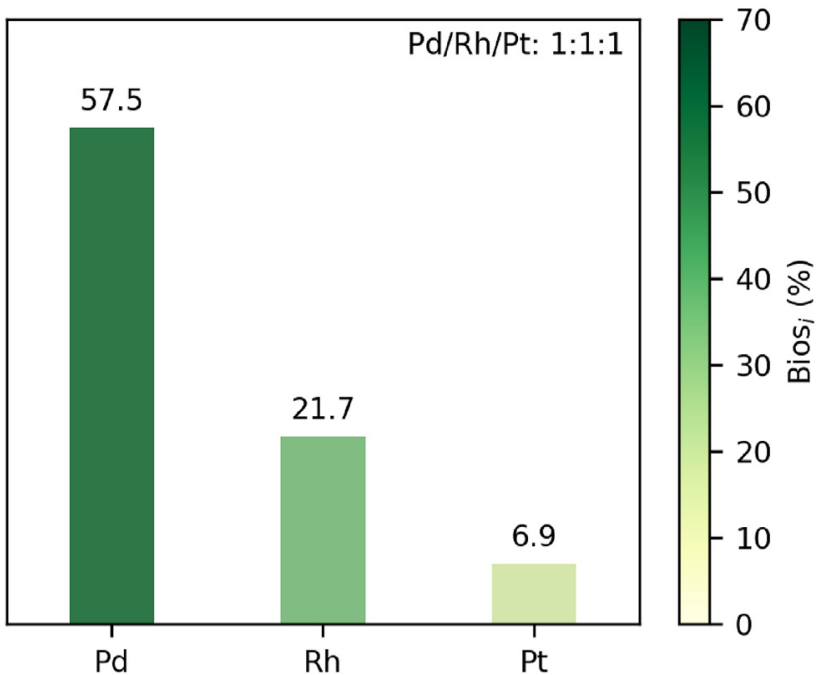

Fig. 10. Competitive biosorption of Pd, Rh and Pt in an equimolar ratio using powdered roots of $E$. crassipes as biosorbent. 


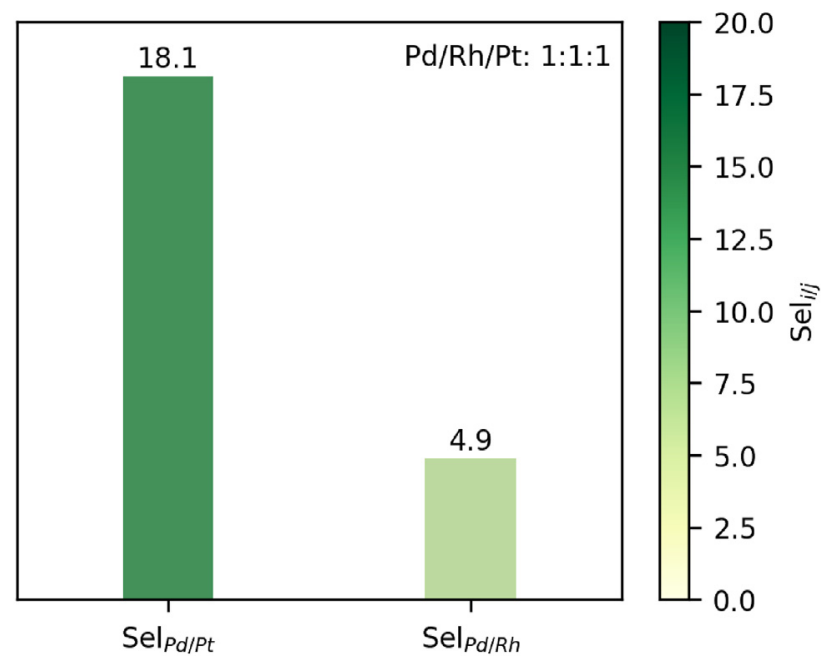

Fig. 11. Selectivity of biosorption of Pd compared to that of Rh and Pt in ternary solution.

metals in the solution other than $\mathrm{i}$ ( $\mathrm{Rh}$ or $\mathrm{Pt}$ ).

Significant differences in selectivity were observed (See SI Table 13 MP-AES assessments with replications and RSD). The first remark is that a selectivity around 2 is already interesting, around 5 is good and around 20 or above is very good. A selectivity of $18(\mathrm{Pd} / \mathrm{Pt})$ in a competitive experiment is therefore very interesting for metals that are often encountered together, and will allow a high level of purification in a small number of runs. A higher degree of selectivity was observed between Pd and Pt (18.1) than between Pd and Rh (4.9), which means that the affinities of Pd and $\mathrm{Rh}$ for E. crassipes are more similar. These results are consistent with those obtained for leaf biomass of T. catappa (Zhang et al., 2019). The effectiveness of biosorption can be described as a process of separation of Pd and Pt. This selectivity is of great interest, especially since most ores are composed of a mixture of Pd and Pt.

\subsection{Potential mechanisms}

These data (biosorption of Pd with different ecomaterials, selectivity of biosorption) exhibit the high affinity of Pd for root powder derived from aquatic plants, especially E. crassipes. Meanwhile, it raises questions: are the observed performances the consequences of functional traits of aquatic plant species (hypothesis 1 ), or the consequences of the chemical reactivity of Pd ${ }^{\mathrm{II}}$ (hypothesis 2)?

\subsubsection{Evaluation of hypothesis 1: a consequence of functional traits of aquatic plant species}

We hypothesized that the high affinity of aquatic plants for Pd can be a consequence of traits specific to these plants, particularly the chemical structure of their roots. We suggest that submerged and amphibious species require root characteristics that allow them to adsorb nutrients with remarkable efficiency. Indeed, nutrients such as iron, magnesium, calcium, and others are found at very dilute concentrations in water. The presence of carboxylate functions at the surfaces of roots allows the efficient capture of ions. It is well known that E. crassipes roots are rich in hemicellulose (Ruan et al., 2016) and thus in carboxylate functions. Recently, we have proven by mathematical fitting of FTIR-ATR assessments that roots of many aquatic plants (M. aquatica, E. crassipes, P. stratiotes, and $L$. peploides) are rich in carboxylate functions (Stanovych et al., 2019). The natural affinity of carboxylate moieties for transition metallic elements is consistent with functional features of aquatic plants and the biosorption performances of their roots. To test this hypothesis, we carried out the esterification of carboxylic functions of root powder derived from E. crassipes (Scheme 1, see SI for more details). The powder was introduced in methanol with a catalytic amount of sulfuric acid. A comparative study of biosorption capacity was performed with $40 \mathrm{mg} \mathrm{g}^{-1}$ of Pd and 1 g.L $\mathrm{L}^{-1}$ of biosorbent (powder of $E$. crassipes roots) as described by Grison et al. (Dong et al., 2015).

The observed decrease in biosorption capacity confirmed the role of carboxylate functions. However, the fact that some biosorption still occurs revealed the participation of other functional groups (or of another mechanism), which could be hinted at also by the non-negligible performance of biosorption at $\mathrm{pH}=3$ (see paragraph 3.6) when the acidic moieties are protonated. We suggest that the specific reactivity of $\mathrm{Pd}^{\mathrm{II}}$ could explain why biosorption capacity was not reduced to zero after esterification or acidification.

\subsubsection{Evaluation of hypothesis 2: a consequence of the chemical} reactivity of $P d$

Pure lignin and pine cones, rich in lignin (group 2), exhibited an interesting affinity for Pd, despite the lack of carboxylate moieties in their composition. One can wonder through which process the Pd is biosorbed on this type of biomass.

The ability of $\mathrm{Pd}^{\mathrm{II}}$ to develop stable complexes with unsaturated systems could provide an explanation. $\mathrm{Pd}^{\mathrm{II}}-\pi$ interactions have already been reported as the driving force for guest encapsulation (Nakajima and Hori, 2014). Rios et al. have described that arenes derived from phenols could form $\pi$-bonds to palladium in a $\eta^{6}$ coordination mode (Rios et al., 2012). Lignin is able to form $\mathrm{Pd}^{\mathrm{II}}-\pi$ interactions (phenyl rings). This could explain why Pd is efficiently biosorbed by lignin and pine cones (group 2). Using theoretical studies based on DFT-HF calculations, we tested the likelihood of formation of such $\mathrm{Pd}^{\mathrm{II}}-\pi$ complexes, in particular for the $\beta-O-4$ lignin model dimer with the studied Pd cation. Our results showed mutual attraction between the lignin model and the Pd salt. Interestingly, results predict a short contact between $\mathrm{Pd}^{\mathrm{II}}$ and the electron-rich ring with a C-Pd distance of $3.43 \AA$ (Fig. 12), close to the van der Waals distance (3.33 $\AA$ ).

The ring $\mathrm{Pd}-\mathrm{C}$ distance is close to the $\mathrm{Pd}-\mathrm{C}$ distance described by Rios et al. (2012) and illustrates clear $\mathrm{Pd}^{\mathrm{II}}-\pi$ enyl interactions that were formed in the stable state. Another significant structural feature is found with the formation of hydrogen bonding $\left(\mathrm{d}_{\mathrm{NH}}\right.$ $\mathrm{o}=1.97 \AA$ ). This result is another indication of a stabilization of the $\pi$ complex.

To confirm this hypothesis, we studied the biosorption of the lignin model with $\mathrm{Pd}^{\mathrm{II}}$. In this experiment, $0.3 \mathrm{mmol}$ of $\beta-0-4$ lignin model dimer was able to sorb $2 \mathrm{ppm}$ of Pd in water.

We can conclude that the second hypothesis (consequence of the chemical reactivity of Pd) can explain the high biosorption of Pd by types of biomass in group 2, being supported by both experimental results and theoretical analyses. This preliminary study opens new perspectives in the rationalization of Pd biosorption.
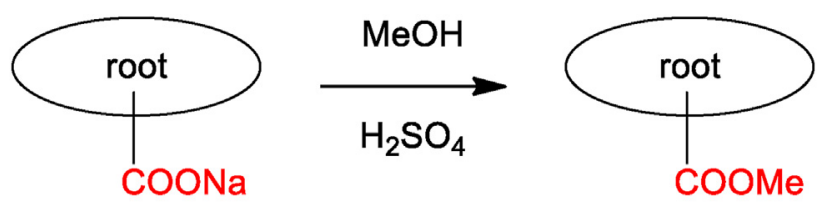

$\mathrm{q}_{\mathrm{e}}=40 \mathrm{mg} \cdot \mathrm{g}^{-1}$

$q_{e}=25 \mathrm{mg} \cdot \mathrm{g}^{-1}$

Scheme 1. Biosorption capacity after esterification of root carboxylic functions. 


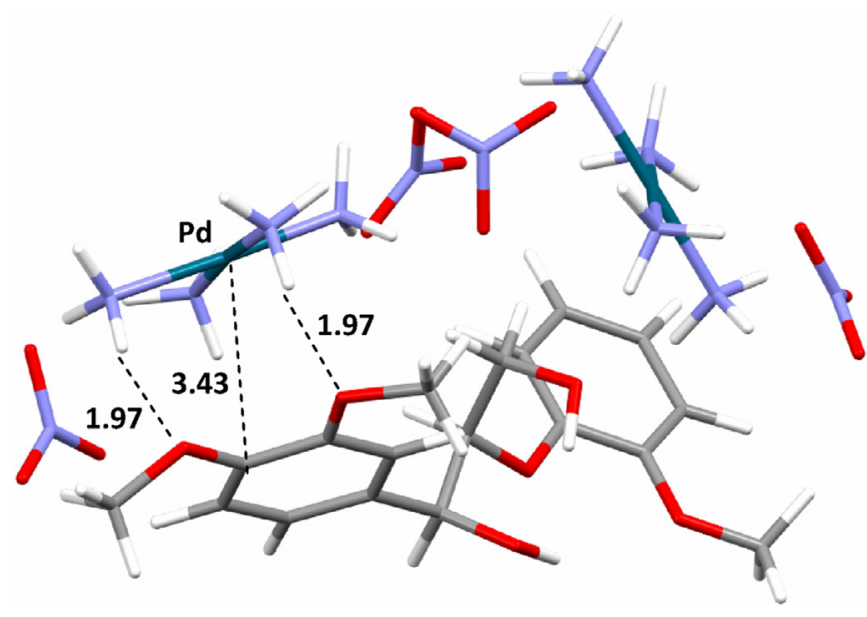

Fig. 12. $\mathrm{Pd}^{\mathrm{II}}-\pi$ enyl interaction and hydrogen bonding between $\mathrm{Pd}$ and the lignin model. Distances in $\AA, \mathrm{C}$ in red, $\mathrm{H}$ in white, $\mathrm{O}$ in red, $\mathrm{N}$ in violet, $\mathrm{Pd}$ in purple.

\section{Conclusion}

Powdered roots of aquatic plants (E. crassipes, P. stratiotes, $L$. peploides, M. aquatica) displayed an excellent capacity for Pd biosorption. Among the two developed processes, namely the batch mode and the fixed-bed column, the latter showed slightly better results. Moreover, a selective separation of $\mathrm{Pd}, \mathrm{Pt}, \mathrm{Ru}$ and $\mathrm{Ir}$ was shown to be possible, and selectivity was surprisingly high from a ternary solution of Pd, Rh and Pt. Interestingly, these three metals, the most valuable of the series, are the ones that showed best biosorption. Ir and Ru could therefore be efficiently separated from the rest of the PGMs.

The process was clean, rapid, efficient, and straightforward to implement, even at neutral $\mathrm{pH}$.

The affinity of biosorbents could result from two processes: the high density of carboxylate functions in roots of aquatic plants and $\mathrm{Pd}^{\mathrm{II}}-\pi$ interactions with the $\beta-O-4$ linkage in native lignin.

The sorbents used are natural, cheap and abundant in nature. The use of E. crassipes, P. stratiotes, and L. peploides as plant filters constitutes an opportunity for the recovery of Pd from invasive plants and provides strong motivation for their harvest and thereby the control of their proliferation.

The robustness and repeatability of the process was ensured by the use of material from dead plants, and the its transformation into powdered form with a controlled granulometry. Biosorption kinetics fit very well the pseudo-second order rate model. These new ecomaterials are ideal for the preparation of future catalysts in organic synthesis.

The inventive combination incorporating biosorption combined with ecocatalysis is a real opportunity for the ecologically sustainable recycling of $\mathrm{Pd}$ and other strategic precious metals. Therefore, an additional outcome of our study is the perspective of identifying conditions that could be scaled up to allow meaningful uses of these processes in green catalysis. This aspect will be the subject of further studies (Adler et al., 2021).

\section{Declaration of competing interest}

The authors declare that they have no known competing financial interests or personal relationships that could have appeared to influence the work reported in this paper.

\section{Acknowledgments}

The authors would like to thank the European Regional Development Fund (FEDER) and the French National Center for Scientific Research (CNRS) for financial support. Sci-GuidEdit and Pr. Doyle McKey are acknowledged for writing assistance and for proofreading the article, respectively.

\section{Sample credit author statement}

Claude Grison: Conceptualization, Methodology.

Claude Grison and Yves-Marie Legrand: Writing- Original draft preparation, Writing- Reviewing and Editing.

Armelle Garcia, Franck Pelissier: Chemical assessments.

Pierre-Alexandre Deyris, Pauline Adler, Timothé Dumas: Biosorption experiments.

Yves-Marie Legrand: DFT calculations.

\section{References}

Adler, P., Dumas, T., Deyris, P.-A., Petit, E., Diliberto, S., Boulanger, C., Grison, C., 2021 From ecological recycling of Pd to greener Sonogashira cross-coupling reactions. J. Clean. Prod. 293, 126164 . https://doi.org/10.1016/j.jclepro.2021.126164 accepted manuscript.

Altundogan, H.S., Arslan, N.E., Tumen, F., 2007. Copper removal from aqueous solutions by sugar beet pulp treated by $\mathrm{NaOH}$ and citric acid. J. Hazard Mater. 149 , 432-439. https://doi.org/10.1016/j.jhazmat.2007.04.008.

Biffis, A., Centomo, P., Del Zotto, A., Zecca, M., 2018. Pd metal catalysts for crosscouplings and related reactions in the 21 st century: a critical review. Chem. Rev. 118, 2249-2295. https://doi.org/10.1021/acs.chemrev.7b00443.

Cerino-Córdova, F.J., Díaz-Flores, P.E., García-Reyes, R.B., Soto-Regalado, E., GómezGonzález, R., Garza-González, M.T., Bustamante-Alcántara, E., 2013. Biosorption of $\mathrm{Cu}(\mathrm{II})$ and $\mathrm{Pb}(\mathrm{II})$ from aqueous solutions by chemically modified spent coffee grains. Int. J. Environ. Sci. Technol. 10, 611-622. https://doi.org/10.1007/s13762013-0198-z.

Chassary, P., Vincent, T., Sanchez Marcano, J., Macaskie, L.E., Guibal, E., 2005. Palladium and platinum recovery from bicomponent mixtures using chitosan derivatives. Hydrometallurgy 76, 131-147. https://doi.org/10.1016/ j.hydromet.2004.10.004.

Chen, X., Lam, K.F., Mak, S.F., Yeung, K.L., 2011. Precious metal recovery by selective adsorption using biosorbents. J. Hazard Mater. 186, 902-910. https://doi.org/ 10.1016/j.jhazmat.2010.11.088.

Chen, Y., Chen, Y., Wu, J., Zhang, J., 2018. The effect of biotic and abiotic environmental factors on Pd(II) adsorption and reduction by Bacillus wiedmannii MSM. Ecotoxicol. Environ. Saf. 162, 546-553. https://doi.org/10.1016/ j.ecoenv.2018.07.043.

Clavé, G., Pelissier, F., Campidelli, S., Grison, C., 2017. Ecocatalyzed Suzuki cross coupling of heteroaryl compounds. Green Chem. 19, 4093-4103. https:// doi.org/10.1039/C7GC01672G.

Cui, J., Zhu, N., Kang, N., Ha, C., Shi, C., Wu, P., 2017. Biorecovery mechanism of palladium as nanoparticles by Enterococcus faecalis: from biosorption to bioreduction. Chem. Eng. J. 328, 1051-1057. https://doi.org/10.1016/ j.cej.2017.07.124.

De Laet, C., Matringe, T., Petit, E., Grison, C., 2019. Eichhornia crassipes: a powerful bio-indicator for water pollution by emerging pollutants. Sci. Rep. 9, 7326. https://doi.org/10.1038/s41598-019-43769-4.

Dong, H., Zhao, J., Chen, J., Wu, Y., Li, B., 2015. Recovery of platinum group metals from spent catalysts: a review. Int. J. Miner. Process. 145, 108-113. https:// doi.org/10.1016/j.minpro.2015.06.009.

Garel, C., Renard, B.-L., Escande, V., Galtayries, A., Hesemann, P., Grison, C., 2015. CC bond formation strategy through ecocatalysis: insights from structural studies and synthetic potential. Appl. Catal., A 504, 272-286. https://doi.org/10.1016/ j.apcata.2015.01.021.

Giri, A.K., Patel, R., Mandal, S., 2012. Removal of Cr (VI) from aqueous solution by Eichhornia crassipes root biomass-derived activated carbon. Chem. Eng. J. 185-186, 71-81. https://doi.org/10.1016/j.cej.2012.01.025.

Grison, C., Carrasco, D., Stanovych, A., 2018. Method for the production of a material of plant origin that is rich in phenolic acids, comprising at least one metal, for carrying out organic synthesis reactions. W02018178374 (A1). https:// worldwide.espacenet.com/publicationDetails/biblio? $\mathrm{FT}=\mathrm{D} \&$ date $=20181004 \& \mathrm{DB}=\mathrm{EPODOC} \&$ locale $=$ en $\mathrm{EP} \& C C=W O \& N R=2018178374 \mathrm{~A} 1 \& \mathrm{KC}=\mathrm{A} 1 \& N D=4$. (Accessed 7 January 2019). 
accessed.

Hunt, A.J., Matharu, A.S., King, A.H., Clark, J.H., 2015. The importance of elemental sustainability and critical element recovery. Green Chem. 17, 1949-1950. https://doi.org/10.1039/C5GC90019K.

Ilyas, S., Srivastava, R.R., Kim, H., Cheema, H.A., 2020. Hydrometallurgical recycling of palladium and platinum from exhausted diesel oxidation catalysts. Separ. Purif. Technol. 248, 117029. https://doi.org/10.1016/j.seppur.2020.117029.

Karim, S., Ting, Y.-P., 2020. Ultrasound-assisted nitric acid pretreatment for enhanced biorecovery of platinum group metals from spent automotive catalyst. J. Clean. Prod. 255, 120199. https://doi.org/10.1016/j.jclepro.2020.120199.

Kyzas, G.Z., Fu, J., Matis, K.A., 2014. New biosorbent materials: selectivity and bioengineering insights. Processes 2, 419-440. https://doi.org/10.3390/ pr2020419.

Lee, J., Kurniawan, Hong, H.-J., Chung, K.W., Kim, S., 2020. Separation of platinum, palladium and rhodium from aqueous solutions using ion exchange resin: a review. Separ. Purif. Technol. 246, 116896. https://doi.org/10.1016/ j.seppur.2020.116896.

Mack, C., Wilhelmi, B., Duncan, J.R., Burgess, J.E., 2007. Biosorption of precious metals. Biotechnol. Adv. 25, 264-271. https://doi.org/10.1016/ j.biotechadv.2007.01.003.

Mallampati, S.R., Lee, B.H., Mitoma, Y., Simion, C., 2018. Sustainable recovery of precious metals from end-of-life vehicles shredder residue by a novel hybrid ball-milling and nanoparticles enabled froth flotation process. J. Clean. Prod. 171, 66-75. https://doi.org/10.1016/j.jclepro.2017.09.279.

Nakajima, K., Hori, A., 2014. Dynamic transformation and reversible guest encapsulations of pseudopolymorphs of a fully fluorinated $\beta$-diketonate $\mathrm{Pd}(\mathrm{II}) \mathrm{com}$ plex. Cryst. Growth Des. 14, 3169-3173. https://doi.org/10.1021/cg500222y.

Negm, N.A., Hefni, H.H.H., Abd-Elaal, A.A., 2017. Assessment of agricultural wastes as biosorbents for heavy metal ions removal from wastewater. In: Biresaw, G., Mittal, K.L. (Eds.), Surfactants in Tribology, first ed., ume 5. CRC Press, Taylor \& Francis Group, 6000 Broken Sound Parkway NW, Suite 300, Boca Raton, FL 33487-2742, pp. 465-491. https://doi.org/10.1201/9781315120829-21.

Ramakul, P., Yanachawakul, Y., Leepipatpiboon, N., Sunsandee, N., 2012. Biosorption of palladium(II) and platinum(IV) from aqueous solution using tannin from Indian almond (Terminalia catappa L.) leaf biomass: kinetic and equilibrium studies. Chem. Eng. J. 193-194, 102-111. https://doi.org/10.1016/ j.cej.2012.04.035.

Rios, B.E., Sood, P., Klichko, Y., Koutha, M., Powell, D., Lattman, M., 2012 A bisphosphonite calix[5] arene ligand that stabilizes $\eta 6$ arene coordination to palladium. Dalton Trans. 41, 6677. https://doi.org/10.1039/c2dt30491k.

Ruan, T., Zeng, R., Yin, X.-Y., Zhang, S.-X., Yang, Z.-H., 2016. Water hyacinth (Eichhornia crassipes) biomass as a biofuel feedstock by enzymatic hydrolysis. BioResources 11, 2372-2380.

Sari, A., Mendil, D., Tuzen, M., Soylak, M., 2009. Biosorption of palladium(II) from aqueous solution by moss (Racomitrium lanuginosum) biomass: equilibrium, kinetic and thermodynamic studies. J. Hazard Mater. 162, 874-879. https:// doi.org/10.1016/j.jhazmat.2008.05.112.

Sheldon, R.A., 2005. Green solvents for sustainable organic synthesis: state of the art. Green Chem. 7, 267-278. https://doi.org/10.1039/B418069K.

Stanovych, A., Balloy, M., Olszewski, T.K., Petit, E., Grison, C., 2019. Depollution of mining effluents: innovative mobilization of plant resources. Environ. Sci. Pollut. Res. 26, 19327-19334. https://doi.org/10.1007/s11356-019-05027-y.

Torborg, C., Beller, M., 2009. Recent applications of palladium-catalyzed coupling reactions in the pharmaceutical, agrochemical, and fine chemical industries. Adv. Synth. Catal. 351, 3027-3043. https://doi.org/10.1002/adsc.200900587.

Verryn, S.M.C., Merkle, R.K.W., 1994. Compositional variation of cooperite, braggite and vysotskite from the Bushveld Complex. Mineral. Mag. 58, 223-234. https:// doi.org/10.1180/minmag.1994.058.391.05.

Younes, I., Rinaudo, M., 2015. Chitin and chitosan preparation from marine sources. Structure, properties and applications. Mar. Drugs 13, 1133-1174. https:// doi.org/10.3390/md13031133.

Zhang, L., Song, Q., Liu, Y., Xu, Z., 2019. Novel approach for recovery of palladium in spent catalyst from automobile by a capture technology of eutectic copper J. Clean. Prod. 239, 118093. https://doi.org/10.1016/j.jclepro.2019.118093.

Zhang, L., Song, Q., Liu, Y., Xu, Z., 2020. An integrated capture of copper scrap and electrodeposition process to enrich and prepare pure palladium for recycling of spent catalyst from automobile. Waste Manag. 108, 172-182. https://doi.org/ 10.1016/j.wasman.2020.04.013.

Zhu, B., Fan, T., Zhang, D., 2008. Adsorption of copper ions from aqueous solution by citric acid modified soybean straw. J. Hazard Mater. 153, 300-308. https:/ doi.org/10.1016/j.jhazmat.2007.08.050. 